học- Trường Đại học Y dược Huế, Tập 6 (02) Số 32/ 2016; Trang: 51.

6. Nguyến Thị Thúy Hằng Nguyễn Hữu Thịnh, Hoàng Bùi Bảo (2014), "Khảo sát một số yếu tố nguy cơ tim mạch và bất thường điện tim, siêu âm tim ở bệnh nhân đang chờ ghép thận", Tại chí y dược học.

7. M. Y. Said, R. M. Douwes, M. van Londen và các cộng sự. (2019), "Effect of renal function on homeostasis of asymmetric dimethylarginine (ADMA): studies in donors and recipients of renal transplants", Amino Acids, 51(3), tr. 565-575.

8. J. Eiselt, D. Rajdl, J. Racek và các công sứ. (2014), "Asymmetric dimethylarginine and progression of chronic kidney disease: a one-year follow-up study", Kidney Blood Press Res, 39(1), tr. 50-7.

9. T. M. Lu, M. Y. Chung, C. C. Lin và các cộng sư. (2011), "Asymmetric dimethylarginine and clinical outcomes in chronic kidney disease", Clin J Am Soc Nephrol, 6(7), tr. 1566-72.

\title{
ĐÁNH GIÁ HIỆU QUẢ PHỐI HỢP MỞ KHE GIỮA VÀ KHE DƯỚI QUA NộI SOI MŨI TRONG ĐIỀU TRI VIÊM XOANG HÀM DO NẤM TẠI BỆNH VIỆN CHỢ RẪY
}

\section{TÓM TẮT}

Giới thiệu: Viêm xoang hàm do nấm hầu hết các chuyên gia TंMH đều găp khi khám lâm sàng. Tỷ lẹ tái phát cao, phát hiên tái phát khó và thâm chí có thể phẫu thuật lại. Để hạn chế điều này, chúng tôi thực hiên kết hợp mở khe giữa và khe dưới qua nội soi mũi để điều trị viêm xoang hàm do nấm. Phương pháp: Với nghiên cứu mô tả cắt ngang từ 9/ 2018 đến 3/2021, chúng tôi đã thực hiện được 55 ca phẫu thuật viêm xoang hàm do nấm với kỹ thuât mở khe giữa và mở khe dưới qua nội soi mũi tại Khoa Tai Mũi Họng Bệnh viên Chợ Rẫy. Kết quả: Qua 55 trường hợp viêm xoang hàm do nấm, thì tỷ lệ nữ chiếm $60 \%$. Các triệu chứng thường găp của viêm xoang hàm do nấm lần lượt chảy dịch mũi $(90,9 \%)$, nghẹt mũi $(85,6 \%)$, đau đầu/ căng tức vùng măt $(81,8 \%)$, thở hôi $(45,5 \%)$. Sau phẫu thuật thì tình trạng cải thiện các triệu chứng đáng kể. Tuy nhiên, vẫn có tỷ lê hẹp lổ mở khe dướ chiếm $16 \%$ tại thời điểm 6 tháng và bít hoàn toàn 7,2\%. Kết luận: Viêc phối hợp mở khe dưới qua nôi soi giúp kiểm soát tốt lòng xoang hàm trong lúc phâu thuật, đảm bảo lấy sạch bệnh tích. Bên canh đó, Viêc mở khe dưới trong điêuu trị nấm xoang hàm còn giúp theo dõi, phát hiện sớm tái phát nấm và xử trí kịp thời hạn chế phải phấu thuật laai cho bênh nhân.

Tư khóa: mở khe dưới, mở khe giữa, viêm xoang hàm do nấm.

\section{SUMMARY}

TO EVALUATE EFFECT OF ENDOSCOPIC COMBINED MIDDLE AND INFERIOR MEATAL ANTROSTOMY TO CURE FUNGAL MAXILLARY SINUSITIS AT CHO RAY HOSPITAL

Introduce: Fungal maxillary sinusitis is commonly in ENT clinic. Recurrence rates arc high after surgery.

*Bênh viện Chơ Rẫy

Chịu trách nhiệm chính: Ngô Văn Công

Email: congtmh@gmail.com

Ngày nhận bài: 25.6.2021

Ngày phản biên khoa hoc: 24.8.2021

Ngày duyệt bài: 31.8.2021
Ngô Văn Công*

It is difficult to diagnosis when fungal maxillary sinusitis recur. Recurrence case may be reoperated. We performed a combination inferior and middle meatotomy to treat fungal maxillary sinusitis and improve ones. Methods: We performed a crosssectional descriptive study from September 2018 to March 2021. There 55 fungal maxillary sinusitis cases were operated a combination nasal endoscopic inferior and middle meatotomy at Cho Ray hospital. Results: There arc 55 fungal maxillary sinusitis cases which female rate is $60 \%$. Common symptoms arc nasal discharges $90.9 \%$, nasal congestion $85,6 \%$, headache $81.8 \%$. Almost of symptoms were improved after surgery. However, there was still rate of inferior meatus opening narrow $(16 \%)$ at $6^{\text {th }}$ month and completely narrow (7.2\%). Conclusion: The combination nasal endoscopic inferior and middle meatotomy control inside of maxillary sinus clearly at operative time, to sure removing fungus in maxillary sinus. In addition, these help following, detect recurring fungus early in maxillary sinus. So, we can cure appreciate treatment to limit reoperation.

Keywords: inferior meatal antrostomy, middle meatal antrostomy, fungal maxillary sinusitis.

\section{I. ĐĂT VẤN ĐỀ}

Viêm mũi xoang là một trong những bệnh lý thường gặp nhất trong Tai Mũi Họng chiếm tỷ lệ 13 - 16\% dân số [10]. Trong đó, viêm xoang do nấm chiếm khoảng $10 \%$ các trường hợp viêm xoang mạn tính, tỷ lệ viêm xoang hàm do nấm chiếm tỷ lệ cao nhất [2]. Với kỹ thuật nội soi mũi xoang đã hố trợ rất nhiều trong việc phẫu thuật nội soi loại bỏ bệnh tích trong xoang mà bảo tồn được nhiều cấu trúc, cho tỷ lệ thành công cao từ 80.5 - 98.4\% [7],[8]. Tuy nhiên, vẫn còn tỉ lệ thất bai hoắc tái phát sau phẫu thuât từ 4.1 $18 \%$ tùy vào nghiên cứu [7]. Trong các nguyên nhân dấn đến thất bại thì tắc lỗ thông xoang hàm được nhiều tác giả đề cập và chiếm tỉ lệ cao như Ramadan $\mathrm{HH}$ 27\% [5], Musy và Kountakis 
39\% [3], GS Phạm Kiên Hữu 79.6\%. Ngoài ra, việc bỏ sót bệnh tích như nấm thường khu trú ở thành trước xoang hàm cũng được các tác giả ghi nhận như GS Phạm Kiên Hữu 3.7\% [11].

Thêm vào đó, việc theo dõi, chăm sóc và phát hiện tái phát nấm trong xoang hàm khó khăn và phát hiên muộn. Phải phụ thuộc nhiều vào $C T$ scan để khảo sát mô nấm tái phát trong xoang hàm. Do đó, để mang lại hiệu quả điều trị và hạn chế các khó khăn trên. Chúng tôi thực hiện kết hợp phẫu thuật mở khe giữa và khe dưới qua nội soi mũi để điều trị viêm xoang hàm do nấm.

\section{II. ĐỐI TƯợNG VÀ PHƯƠNG PHÁP NGHIÊN CỨU}

Nghiên cứu thực hiện trên 55 trường hợp viêm xoang hàm do nấm từ $8 / 2018$ đến $5 / 2021$ được chẩn đoán viêm xoang hàm do nấm và được điều trị phẫu thuật nội soi mũi xoang tại Khoa Tai Mũi Họng - Bệnh viện Chợ Rẫy. Các bệnh nhân đủ từ 18 tuổi trở lên, đã được xét nghiệm, nội soi, chụp CT scan đánh giá trước mổ và cấy mổ bệnh phẩm có kết quả là nấm sau phẫu thuật.

\section{KẾT QUẢ NGHIÊN CỨU}

\subsection{Hình ảnh mở khe dưới qua nội soi mũi}

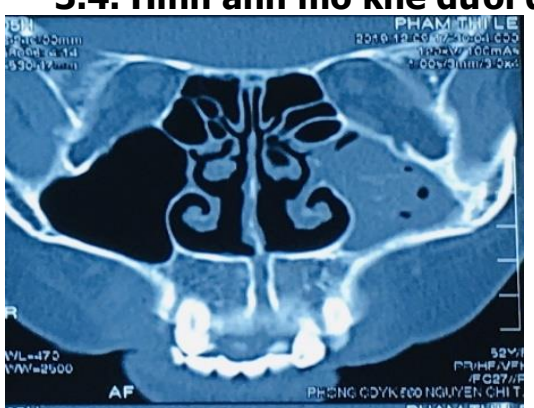

Viêm xoang hàm trái do nấm

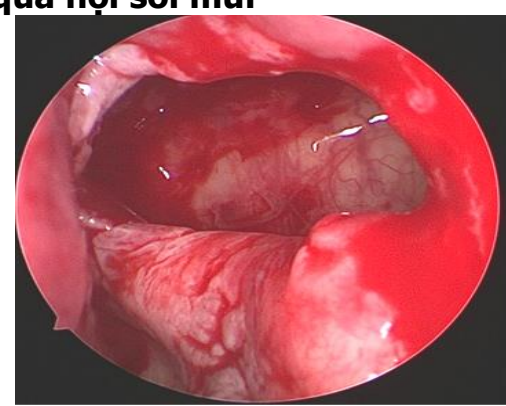

Mở khe dưới qua nôii soi
3.1. Phân bố theo nhóm tuổi

\begin{tabular}{|c|c|c|c|c|}
\hline $\begin{array}{c}\text { Nhómm } \\
\text { tuối }\end{array}$ & $\leq \mathbf{2 0}$ & $\begin{array}{c}\mathbf{2 1 -} \\
\mathbf{4 4 0}\end{array}$ & $\begin{array}{c}\mathbf{4 1 -} \\
\mathbf{6 0 0}\end{array}$ & $>\mathbf{6 0}$ \\
\hline $\mathrm{Nam}$ & 0 & $3(5,5 \%)$ & $12(21,8 \%)$ & $7(12,7 \%)$ \\
\hline $\mathrm{Nữ}$ & $2(3,6 \%)$ & $6(11 \%)$ & $18(32,7 \%)$ & $7(12,7 \%)$ \\
\hline $\mathrm{N}(\%)$ & $2(3,6 \%)$ & $9(16,4 \%)$ & $30(54,5 \%)$ & $14(23,3 \%)$ \\
\hline
\end{tabular}

3.2. Phân bố triệu chứng lâm sàng của bệnh nhân

\begin{tabular}{|c|c|c|c|}
\hline & Trước mố & 3 tháng & $\mathbf{6}$ tháng \\
\hline Chảy mũi & $50(90,9 \%)$ & $3(5,5 \%)$ & $2(3,6 \%)$ \\
\hline Nghẹt mũi & $47(85,5 \%)$ & $2(3,6 \%)$ & $1(1,8 \%)$ \\
\hline Giảm khứu & $12(21,8 \%)$ & 0 & 0 \\
\hline Nặng/căng đau & 45 & 3 & 1 \\
vùng mă̆t & $(81,8 \%)$ & $(5,5 \%)$ & $(1,8 \%)$ \\
\hline Hắc hơi & $18(32,7 \%)$ & $3(5,5 \%)$ & $3(5,5 \%)$ \\
\hline Ngứa mũi & $15(27,3 \%)$ & $2(3,6 \%)$ & $2(3,6 \%)$ \\
\hline Ngứa mắt/chảy & 10 & 2 & 2 \\
nước mắt/sung huyết & $(18,2 \%)$ & $(3,6 \%)$ & $(3,6 \%)$ \\
\hline Ngứa tai/ ù tai & $3(5,5 \%)$ & $1(1,8 \%)$ & $1(1,8 \%)$ \\
\hline Thở hối & $25(45,5 \%)$ & 0 & 0 \\
\hline 3.3. Tỷ lệ tái phát và hẹp \\
\begin{tabular}{|c|c|c|}
\hline \multicolumn{4}{|c|}{$\mathbf{3}$ tháng } & $\mathbf{6}$ tháng \\
\hline Tái phát & $1(1,8 \% \%)$ & $3(5,4 \%)$ \\
\hline Hẹp lố mở khe dưới & $4(7,2 \%)$ & $9(16 \%)$ \\
\hline Bít hoàn toàn khe dưới & $2(3,6 \%)$ & $4(7,2 \%)$ \\
\hline
\end{tabular}
\end{tabular}

Hình 1: hình ảnh mở khe dưới qua các thời điểm

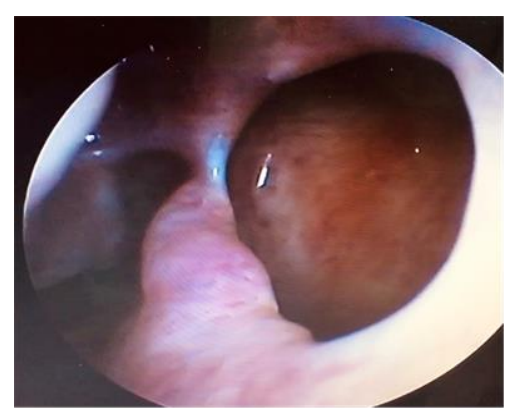

Mở khe dưới sau 6 tháng

\section{BÀN LUẬN}

1. Triệu chứng lâm sàng. Qua khảo sát 55 trường hợp viêm xoang hàm do nấm, tuổi thường gặp 40 - 60 tuổi chiếm $54,5 \%$ các trường hợp, và nữ chiếm $60 \%$ các trường hợp.

Các triệu chứng viêm xoang hàm do nấm biểu hiện hầu hết các triệu chứng của mũi xoang, trong đó thường gặp nhất là chảy dịch mũi $(90,9 \%)$, nghẹt mũi $(85,6 \%)$, đau đâu/ căng tức vùng mặt $(81,8 \%)$, thở hôi $(45,5 \%)$ và hắc hơi $(32,7 \%)$ và có một số trường hợp giảm khứu $(21,8 \%)$, ngứa mũi $(27,3 \%)$ và triệu chứng mắt $(18,2 \%)$. Đây là nhóm biểu hiện triệu chứng mắt hay là triệu chứng của viêm mũi dị ứng. Sau phẫu thuật thì hầu hết các triệu chứng giảm đáng kể như triệu chứng thở hôi, giảm khứu gần như bớt hoàn toàn, các triệu chứng còn lại giảm đáng kể. Chỉ còn một số triệu chứng ngứa mũi, chảy mũi và hắc hơi vẫn còn ở một số trường hợp. Có thể đây là các triệu chứng của viêm mũi dị ứng trên bệnh nhân viêm xoang hàm do nấm. Tuy nhiên, các triệu chứng dễ chịu hơn rất nhiều so với trước phẫu thuật, mức độ và tần suất bi cải thiện rõ rệt hơn. Và các triệu chứng dị ứng cải thiện nhiều, có thể do một phần tác nhân nấm trong xoang hàm ảnh hưởng lên các triệu chứng dị ứng của bệnh nhân. Sau khi phẫu thuật lấy hết bệnh tích, thì các triệu chứng cải thiện tốt.

2. Đặc điểm xoang hàm qua nội soi. Trong quá trình phẫu thuật nội soi lấy bệnh phẩm 
nấm trong xoang hàm, chúng tôi kết hợp mở khe dưới qua nội soi. Với việc mở khe dưới giúp quan sát, đánh giá tình trạng của lòng xoang hàm trong và sau phẫu thuất rõ ràng, chính xác qua nội soi lỗ mở khe dưới. Điều này khó thực hiện tốt khi khảo sát qua lỗ mở khe giữa. Quan sát tốt lòng xoang hàm sau phẫu thuật giúp cho việc theo dõi bệnh tốt hơn, phát hiện sớm mà không cần phải chụp $\mathrm{CT}$ scan để đánh giá, khi bệnh tái phát cũng có thể điêu trị dễ dàng chăm sóc qua lỗ mở khe dưới, hạn chế việc phải phẫu thuật lại cho bênh nhân.

Nhìn chung, các dấu hiệu về tình trạng của xoang hàm sau phẫu thuật đạt kết quả cao, có thể do bệnh nhân được giải quyết triệt để bệnh tích trong xoang, được dặn dò chu đáo về chế độ chăm sóc trước khi xuất viện và tái khám đúng hẹn. Tuy nhiên, trong nghiên cứu của chúng tôi, tỷ lệ hep lổ mở khe dưới chiếm $16 \%$ tai thời điểm 6 tháng và bít hoàn toàn $7,2 \%$, tương tự với các nghiên cứu của Ramadan $\mathrm{HH} 27 \%[5]$, Musy và Kountakis [3]. Do đó, để hạn chế việc này, chúng tôi sử dụng vạt niêm mac vách mũi xoang phủ lại vào trong lòng xoang hàm qua lổ mở khe dưới để hạn chế việc hẹp và tắc. Một số nghiên cứu nước ngoài về phẫu thuật này bước đầu cho kết quả khả quan, cho thây sự hiệu quả cao trong điều trị bệnh lý xoang hàm nói chung và viêm xoang hàm do nấm nói riêng, đặc biệt hiệu quả cao trong bệnh lý viêm xoang hàm do nấm [6]; Landsberg $\mathrm{R}$ [12] và Ochi $\mathrm{K}$ [4] đã ghi nhận không có hiện tượng dẫn lưu vòng xảy ra, tất cả đều được dẩn lưu qua lỗ mở khe giữa và một số có dẫn lưu thêm qua lỗ mở khe dưới; Albu S [1]cho rằng phương pháp này giúp cho sự thoát dịch và thông khí xoang hàm được tốt hơn; Suzuki $M$ [9] cho rằng việc tạo vạt niêm mạc đã góp phần quan trọng cho sự thành công của phẫu thuật, hạn chế lỗ mở khe dưới bị hẹp hoặc bít lại.

Khi bệnh nhân tái khám và than phiền có triệu chứng xuất tiết qua mũi nhiều hơn và có từng đau đầu nhe từng cơn. Chúng tôi nội sợ thì có xuất hiện nấm trong xoang hàm đã phẩu thuật chiếm khoảng $1,8 \%$ - 5,4\%. Các trường hợp này, chúng tôi phát hiện sớm qua nội soi khe dưới mà không cần chụp CT scan để khảo sát. Chúng tôi bơm rửa và hút sạch mô nấm, màu xanh ở trong lòng xoang ra toàn bộ, mà không cần phải phẫu thuật lại. Bệnh nhân được theo dõi, ổn định cho đến hiền tai.

3. Đặc điểm biến chứng sau phẫu thuật. Trong nghiên cứu của chúng tôi không ghi nhận trường hợp nào có tổn thương ống lệ ty. Việc xác định lố đổ ống lệ ty trong khe dưới trước khi thực hiên mở khe dưới là rất quan trong nhằm tránh biến chứng này. Và tỷ lệ chảy máu sau mổ không xảy ra.

\section{KẾT LUÂN}

Việc phổi hợp mở khe giữa và khe dưới qua nội soi mũi trong điều trị viêm xoang hàm do nấm cho kết quả khả quan. Việc phối hợp mở khe dưới qua nội soi giúp kiểm soát tốt lòng xoang hàm trong lúc phẫu thuật, đảm bảo lấy sạch bênh tích. Bên cạnh đó, Việc mở khe dưới trong điều trị nấm xoang hàm còn giúp theo dõi, phát hiện sớm tái phát nấm và xử trí kịp thời hạn chế phải phẫu thuật lại cho bệnh nhân.

\section{TÀI LIỆU THAM KHẢO}

1. Albu S., Gocea A., Necula S. (2011), Simultaneous inferior and middle meatus antrostomies in the treatment of the severely diseased maxillary sinus. Am J Rhinol Allergy, 25 (2), e80-5.

2. Karthikeyan P., Nirmal Coumare V. (2010), Incidence and presentation of fungal sinusitis in patient diagnosed with chronic rhinosinusitis. Indian journal of otolaryngology and head and neck surgery : official publication of the Association of Otolaryngologists of India, 62 (4), 381-385.

3. Musy P. Y., Kountakis S. E. (2004), Anatomic findings in patients undergoing revision endoscopic sinus surgery. Am J Otolaryngol, 25 (6), 418-22.

4. Ochi K., Sugiura N., Komatsuzaki Y., Nishino H., Ohashi T. (2003), Patency of inferior meatal antrostomy. Auris Nasus Larynx, 30 Suppl, S57-60.

5. Ramadan H. H. (1999), Surgical causes of failure in endoscopic sinus surgery. Laryngoscope, 109 (1), 27-9.

6. Sawatsubashi M., Murakami D., Umezaki T., Komune S. (2015), Endonasal endoscopic surgery with combined middle and inferior meatal antrostomies for fungal maxillary sinusitis. ] Laryngol Otol, 129 Suppl 2, S52-5.

7. Senior B. A., Kennedy D. W., Tanabodee J., Kroger H., Hassab M., Lanza D. (1998), Longterm results of functional endoscopic sinus surgery. Laryngoscope, 108 (2), 151-7.

8. Sobol S. E., Wright E. D., Frenkiel S. (1998), One-year outcome analysis of functional endoscopic sinus surgery for chronic sinusitis. J Otolaryngol, 27 (5), 252-7.

9. Suzuki M., Matsumoto T., Yokota M., Toyoda K., Nakamura Y. (2019), Transnasal inferior meatal antrostomy with a mucosal flap for postCaldwell-Luc mucoceles in the maxillary sinus. J Laryngol Otol, 133 (8), 674-677.

10. Hoàn Mai Quang, Khảo sát đặc điểm lâm sàng, cân lâm sàng và điếu tri viêm mữi xoang do nấm tại bệnh viện Chợ Râyy từ tháng 7/2017 đến tháng 5/2018, in Luận văn Thạc sĩ Y học2018.

11. Hữu, Pham Kiên (2008), Nghiên cứu bênh hoc 27 trướng hợp viêm xoang tái phát sau mổ tại bênh viện dại học Y dược. Y Hoc TP. Hồ Chí Minh,12,19-22.

12. Landsberg R., Warman M., Margulis A., Masalha M. (2019), The Rationale for Endoscopic Inferior Meatal Antrostomy. ORL, 81 (1), 41-47. 